\title{
Hepatoprotective, antihyperglycemic and antidiabetic effects of Dendrophthoe pentandra leaf extract in rats
}

\author{
Mahadi Hasan ${ }^{1 \dagger}$, Mohammad Tuhin $\mathrm{Ali}^{\mathrm{i}^{* \dagger}}$ (D), Rifat Khan ${ }^{3}$, Parag Palit ${ }^{2}$, Aminul Islam $^{3}$, Veronique Seidel ${ }^{4}$, \\ Rabeya Akter ${ }^{1}$ and Laizuman Nahar ${ }^{1}$
}

\begin{abstract}
Background: Dendrophthoe pentandra (L.) Miq. is a mistletoe species used in traditional medicine. Juice of leaves is used in wound healing, skin infection and cancer; whereas the whole plant is used to treat hypertension and cough. D. pentandra leaf extract has attracted interest due to its pharmacological properties including antioxidant, cytotoxicity and anti-inflammatory effects. In this study, we have investigated the hepatopotective, antihyperglycemic and antidiabetic potential of $D$. pentandra leaf extracts in rats.

Methods: D. pentandra leaf methanolic extract (DPLME) at a fixed dose of $400 \mathrm{mg} / \mathrm{kg}$ body weight was evaluated for its effects on fasting glucose levels of rats. DPLME at the same dose was also used to determine the antidiabetic potential in alloxan-induced diabetic rats and the hepatopotective effects on Paracetamol (PCM) intoxicated rats.

Results: Oral administration of DPLME exhibited a significantly notable oral glucose tolerance in rats. Single doses of the DPLME displayed very significant antidiabetic activity which was comparable to the activity of the standard antihyperglycemic agent Metformin (MET). DPLME also offered significant hepatoprotection to PCM-intoxicated rats at levels commensurable to the standard hepatoprotective drug Silymarin (SIL).

Conclusions: The results of the present study showed that the DPLME possesses hepatopotective, antihyperglycemic and antidiabetic activity. All these results could be due to the presence of the bioactive components in the extract and this warrant further investigation on the nature of the phytochemical(s) responsible for the observed effects.
\end{abstract}

Keywords: Dendrophthoe pentandra, Oral glucose tolerance test, Antidiabetic activity, Hepatoprotective activity

\section{Background}

Dendrophthoe pentandra is a hemiparasitic woody shrub that belongs to the Loranthaceae family of mistletoes and is commonly found on tropical trees [1]. This plant has been extensively used in folklore medicine despite being commonly considered as an unwanted plant due to its parasitic nature. It is widely distributed in China, Cambodia, India, Indonesia, Laos, Malaysia, Myanmar, Philippines, Thailand, and Vietnam [2]. In Indonesia, the leaves of D. pentandra has been reported used in the traditional medicine to treat wounds and skin infection; while whole part of the plant is

\footnotetext{
* Correspondence: m.tuhinali@gmail.com

${ }^{\dagger}$ Mahadi Hasan and Mohammad Tuhin Ali contributed equally to this work. ${ }^{2}$ Department of Biochemistry and Molecular Biology, Faculty of Biological Sciences, University of Dhaka, Dhaka 1000, Bangladesh

Full list of author information is available at the end of the article
}

used to cure hypertension and cough [3]. It is also used for its antidiuretic activity in Indonesian traditional medicine [1]. In Sulawesi Island, this plant has been used as medicine to cure cancer [3]. Previous investigations on this species have demonstrated that the $D$. pentandra leaf extract stimulated the proliferation of mice splenocytes and thymocytes in a time- and dose-dependent manner [4]. Artanti et al. reported the antioxidant activity of this plant on the basis of DPPH free radical scavenging ability and later confirmed the exact chemical identity of the active antioxidant to be quercetin-3-O-rhamnoside, a flavonol glycoside on the basis of isolation and multiple spectrophotometric techniques [2]. Consequent phytochemical analysis revealed that flavonoids are the main active fraction of the leaf extracts of $D$. pentandra. The existence of other plant 
secondary metabolites including: saponins and tannins being present in extracts of solvents of varying polarity $[1,2]$.

There has been a worldwide upsurge in the incidence of diabetes mellitus. It is projected to rise from 171 million in 2000 to 366 million in 2030 [5]. Diabetes mellitus is a metabolic disorder of multiple etiologies in which chronic hyperglycemia results from absent or inadequate pancreatic insulin secretion, with or without concurrent impairment of insulin action [6]. Long-term complications associated with hyperglycemia, such as retinopathy, neuropathy and angiopathy, result in significant disability and mortality [7]. Standard treatments to tackle diabetes include recombinant insulin and oral antidiabetic drugs, but these are faced with challenges such as ensuring adequate production of insulin to meet the soaring demands and difficult patient compliance due to the recurrent side effects of antidiabetic drugs [8, 9]. Hepatic diseases refer to aberrations of the structure or changes in the biochemical activity of liver cells. They occur in almost every age group and account for a global mortality of one million in 2010 [10]. Despite the immense advancements in the field of modern medicine, the absence of potent and effective hepatoprotective agents has remained a constant issue [11].

A large number of medicinal preparations based on plants are recommended for the treatment of hyperglycemia and for their hepatoprotective effect [12, 13]. The World Health Organization (WHO) expert committee on diabetes has listed as one of its recommendations that traditional methods of treatment for diabetes should be further investigated [14]. On the other hand, natural products are also an invaluable pool of molecular scaffolds to discover new drug leads and most currently marketed drugs derive directly or indirectly from plant constituents [15]. As a part of our ongoing research of pharmacological screening of the Bangladeshi medicinal plants, the methanolic extract of D. pentandra had been chosen for the present study. In this study, we have investigated the hepatopotective, antihyperglycemic and antidiabetic potential of $D$. pentandra leaf extracts in rats for the first time. We concluded for further study for the identification of key active compounds responsible for the observed effects.

\section{Methods}

\section{Plant material}

Fresh leaves of D. pentandra (L.) Miq were collected from the Gazipur district, Bangladesh. Subsequent botanical identification and verification was completed at the Bangladesh National Herbarium, Mirpur-1, Dhaka, Bangladesh (DACB Accession no. 45823).

\section{Preparation of the plant extracts}

Leaves were thoroughly washed with water, chopped into small pieces and air-dried for 4 days. The dried material was ground to a fine powder and stored in an air-tight container for further use. Extracts were prepared as described previously [16]. Briefly, dried powdered D. pentandra leaves $(300 \mathrm{~g})$ were extracted at room temperature with methanol at a ratio of 1:4 (powder/ solvent) in a flat-bottom glass container with occasional shaking for 4 days. The extracts were subsequently filtered through a cotton plug and then through Whatman's no.1 filter paper. The resulting filtrate was concentrated to dryness under reduced pressure.

\section{Animals}

Swiss albino rats (80-115 g) of either sex, aged 7-8 weeks, were purchased from the animal research branch of the International Centre for Diarrhoeal Disease and Research, Bangladesh (ICDDR'B). The animals were kept under standard conditions of $25 \pm 3{ }^{\circ} \mathrm{C}$, relative humidity $35-$ $60 \%$ and on a $12 \mathrm{~h}$ dark/light cycle for 1 week before and during the experiments. A standard rodent diet (Lipton, India) was provided with ad libitum administration of water. Food intake was withdrawn $18-24 \mathrm{~h}$ prior to the start of the experiments. All experiments were performed in accordance with the Ethical Principles and Guidelines for Scientific Experiments on Animals (1995) formulated by The Swiss Academy of Medical Sciences and the Swiss Academy of Sciences. The experimental period lasted for eight weeks.

\section{Oral glucose tolerance test (OGTT)}

Tests were carried out according to a previously described protocol with some minor modifications [17]. Swiss albino rats that had fasted for $16 \mathrm{~h}$ prior to the experiment were randomly divided into three groups each containing four rats. Group III was orally administered with DPLME $400 \mathrm{mg} / \mathrm{kg}$ body weight followed by oral administration of $1 \mathrm{~g} / \mathrm{kg}$ glucose solution. The standard group (Group II) was treated with the antihyperglycemic drug MET (Square Pharmaceuticals Ltd., Kaliakoir, Bangladesh) at a dose of $50 \mathrm{mg} / \mathrm{kg}$ body weight, followed by $1 \mathrm{~g} / \mathrm{kg}$ oral glucose administration while the control group (Group I) received no glucose solution. Blood samples were subsequently collected from tail veins at 0 , 30, 60, and $120 \mathrm{~min}$ following oral glucose administration and glucose levels were measured using a glucometer test strip [18].

\section{Antidiabetic activity}

The antidiabetic activity of DPLME was evaluated according to a previously published method [19]. Non-diabetic and alloxan-induced diabetic rats were used in the experiment and were divided into four groups consisting of six rats in each group. Group I was the non-diabetic control group, Group II was the alloxan-induced diabetic control group. Diabetic rats in 
Group III were treated with MET $50 \mathrm{mg} / \mathrm{kg}$ body weight. Diabetic rats in Group IV were orally administered with DPLME at a concentration of $400 \mathrm{mg} / \mathrm{kg}$ body weight. Following a period of $2 \mathrm{~h}$, all rats were orally administered of $1 \mathrm{~g} / \mathrm{kg}$ glucose solution. All treatments were carried out for seven consecutive days. At the end of the experimental period, all surviving animals were fasted overnight. Blood samples were collected from the tail veins at $0,30,60$, and 120 min following glucose administration for five successive days and glucose levels were measured using a standard glucose oxidase test [20].

\section{PCM-induced hepatotoxicity and analysis of liver function parameters}

The hepatoprotective activity of $D$. pentandra leaf extract was evaluated according to a previously published method [21]. Rats were divided into four groups with four rats in each group. Group I received no treatment and served as the control group. Group II was administered PCM (Beximco Pharmaceuticals Ltd., Tongi, Bangladesh) in normal saline at a dose of $20 \mathrm{mg} / \mathrm{kg}$ body weight. Group IV was orally administered with DPLME at the dose of $400 \mathrm{mg} / \mathrm{kg}$ body weight. Group III was treated with the hepatoprotective drug SIL (Radiant Nutraceuticals Ltd., Dhaka, Bangladesh) at a dose of $40 \mathrm{mg} / \mathrm{kg}$ body weight. All treatments lasted for seven consecutive days. On the fifth day of the respective treatments, PCM at a dose of $20 \mathrm{mg} / \mathrm{kg}$ body weight was administered and the animals were sacrificed $48 \mathrm{~h}$ later. Blood samples were collected, allowed to clot and then centrifuged to obtain serum samples. The levels of key liver function parameters including aspartate aminotransferase (AST), serum alanine aminotransferase (ALT), total cholesterol and total protein were measured using commercial assay kits (Span Diagnostic, Surat) [22].

\section{Statistical analyses}

In all cases the experimental values are expressed as mean \pm SEM (Standard error of the mean). One-way analysis of variance (ANOVA) followed by the Dunnett Multiple Comparison t-test was used for statistical comparison. Here, $\mathrm{p}(p$-value $) \leq 0.05$ was considered as statistically significant difference when any group of rats compared with the control group rats. All statistical analysis was done using GraphPad Prism software (version 5.01) from GraphPad Software, Inc., San Diego California, USA.

\section{Results}

\section{Oral glucose tolerance test (OGTT)}

The results of the OGTT performed in rats are summarised in Table 1 and illustrated in Fig. 1. We observed that at the ultimate $120 \mathrm{~min}$ interval following oral glucose intake, the rats that had received the DPLME $400 \mathrm{mg} / \mathrm{kg}$ was able to metabolise glucose more efficiently than those in the standard group that had received the antihyperglycemic drug MET $50 \mathrm{mg} / \mathrm{kg}$. The blood glucose levels of rats from group III decreased significantly in compared to the control group I $(p<0.05)$. The rats from group III, in particular, that had received the DPLME showed a greater ability to metabolise glucose as depicted by the sharp reduction in their blood glucose levels at different intervals throughout the entire time span of $120 \mathrm{~min}$.

\section{Antihyperglycemic activity}

The data obtained are summarized in Table 2 and illustrated in Fig. 2. We observed that the rats from Group IV treated with DPLME showed distinctly reduced blood glucose levels compared with the diabetic control group $(p<0.001)$. Animals in Group IV treated with the DPLME $400 \mathrm{mg} / \mathrm{kg}$ had the lowest blood glucose levels throughout the entire five-day period. The progression rate in the decrease of blood glucose levels in rats of Group IV was found to parallel that observed in the rats of Group III that had received the standard antihyperglycemic drug MET. From the third day of administration onwards, we found that the DPLME $400 \mathrm{mg} / \mathrm{kg}$ (Group IV) could lower blood glucose in diabetic rats to a level that is comparable to the steady blood glucose level of non-diabetic rats (Group I). On the fifth day of administration, the rats in Group IV also had blood glucose levels lower than that in the corresponding control group (Group I) and the group receiving the MET (Group III). This data demonstrates an evident anti-hyperglycemic activity and a potential anti-diabetic role of DPLME.

\section{Effects of extracts on key liver function parameters}

The results of the protective effect of $D$. pentandra extracts on PCM-induced hepatotoxicity are shown in Table 3 and illustrated in Fig. 3. The rats that had received DPLME (group IV) along with the rats treated with the hepatoprotective drug, SIL (group III) showed liver function parameters at levels similar to the untreated control group (group I). However, the rats from Group IV treated with DPLME at a concentration of $400 \mathrm{mg} / \mathrm{kg}$ displayed distinct reductions in the levels of the different liver function parameters compared with the PCM-intoxicated group (Group II) and to levels that are comparable to the levels observed for the group treated with the standard hepatoprotective drug, SIL (group III) $(p<0.05)$. Therefore, it can be suggested that DPLME offers hepatoprotection up at a concentration of $400 \mathrm{mg} / \mathrm{kg}$ at levels commensurable to that observed for SIL. 
Table 1 Effect of methanolic leaf extract of D. pentandra on fasting Rats after oral glucose intake

\begin{tabular}{|c|c|c|c|c|}
\hline \multirow[t]{2}{*}{ Groups } & \multicolumn{4}{|c|}{ Serum glucose level (mg/dl) } \\
\hline & $0 \mathrm{~min}$ & $30 \mathrm{~min}$ & $60 \mathrm{~min}$ & $120 \mathrm{~min}$ \\
\hline Group I: Control group & $90.18 \pm 1.32$ & $261.00 \pm 2.22$ & $275.40 \pm 2.34$ & $291.60 \pm 1.68$ \\
\hline Group II: MET 50 mg/kg & $91.98 \pm 1.20$ & $142.20 \pm 0.66^{*}$ & $133.20 \pm 0.90^{*}$ & $135.00 \pm 1.14^{*}$ \\
\hline Group III: DPLME 400 mg/kg & $126.00 \pm 7.44$ & $111.60 \pm 3.78^{*}$ & $117.00 \pm 4.62^{*}$ & $103.50 \pm 4.08^{*}$ \\
\hline
\end{tabular}

Data are expressed as mean \pm standard error of the mean (SEM) $(n=4) .{ }^{*} p<0.05$ denotes statistically significant result for a group when it was compared with the hyperglycemic control group (Group I)

\section{Discussion}

Medicinal plants have remained integral components of traditional systems of medicine in many countries worldwide and are still relied upon today for various healthcare and medicinal needs [23]. Many plant-derived substances can serve as leads or precursors for the synthesis of modern drugs and have been reported to alleviate a range of ailments including diabetes and hepatic injuries [24, 25]. Hyperglycemia is the result of either insulin deficiency or insulin resistance that confers a reduced ability of liver and muscle cells to store glucose [26]. Though oral antihyperglycemic agents are widely used in practice, they present some disadvantages owing to their poor pharmacokinetic attributes and accompanying side effects [27].

Several biological activities of the extracts of $D$. pentandra have been already reported in a number of previous literatures. According to Endharti et al., the $D$. pentandra methanolic leaf extract containing quercetin has therapeutic potential to ameliorate TNBS (2,4,6-trinitrobenzene sulfonic acid) induced colitis syndrome in mice. It was also reported that

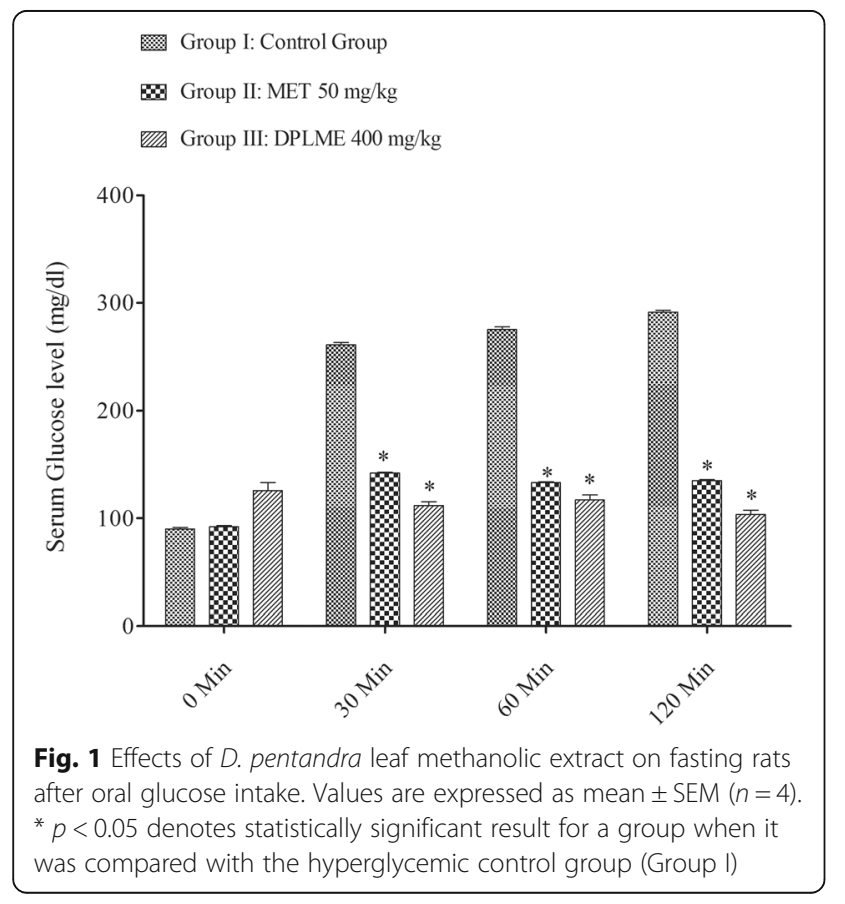

the same extract can inhibit the differentiation of Th17 cells by inhibiting IL-17 production. These findings suggest that the extract of this plant has the important role in inhibiting intestinal inflammation [1]. Extracts of $D$. pentandra have also been reported to effectively inhibit inflammation, proliferation and induce p53 expression on mice models of colitis-associated colon cancer [28].Analysis of cytotoxicity revealed that the extracts of $D$. pentandra had cytotoxic effects on $\mathrm{K} 562$ and MCM-B2 cell lines thus suggestive of a potential anticancer activity of this plant [29]. Methanolic extracts of $D$. pentandra leaves have been also found to exert potent anti-proliferative effects on BCR/ABL-Positive and Imatinib Resistant Leukemia Cell lines [30]. On the other hand, Artanti et al. observed significant antioxidant activities for the methanolic extracts and identified an active flavonol glycoside, quercetin-3-O-rhamnoside as antioxidant where as anti-diabetic activity had been exhibited by both the methanolic and aqueous extracts [3].

In our OGTT, which measures the body's ability to metabolise glucose and clear it out of the bloodstream [17], D. pentandra methanolic leaf extracts showed prominent activity. Extracts also exhibited some potential for controlling diabetes via significant antihyperglycemic activity at a concentration of $400 \mathrm{mg} / \mathrm{kg}$ in comparison to the standard drug MET, an oral antihyperglycemic agent used in addition to regulation in diet and exercise for the management of type 2 (non-insulin dependent) diabetes mellitus [31]. It has been already discussed that the main active bioactive components in the $D$. pentandra leaf extract are flavonoids. Presence of flavonoids in the $D$. pentandra extract explains its different biological and pharmacological activities [1, 2]. According to Fitrilia et al., different extracts of $D$. pentandra was found out to be rich in flavonoids, tannins and saponins [32]. Most recently, Yee et al. in [33] also reported the presence various phytochemicals including alkaloids, flavonoids, saponins, and tannins in the ethyl acetate leaf extract of this plant. Other extracts of plants indigenous to the Indian sub-continent such as, Allium cepa, Allium sativum, Cajanus cajan, Coccinia indica, have been attributed some 
Table 2 Effect of methanolic leaf extract of D. pentandra on Alloxan induced diabetic Rats

\begin{tabular}{llllll}
\hline Groups & \multicolumn{5}{l}{ Serum glucose level $(\mathrm{mg} / \mathrm{dl})$} \\
\cline { 2 - 5 } & Day 1 & Day 2 & Day 3 & Day 4 & Day 5 \\
\hline Group I: Nondiabetic control & $91.80 \pm 1.02^{* * *}$ & $102.06 \pm 2.82^{* * *}$ & $89.64 \pm 0.78^{* * *}$ & $99.00 \pm 2.10^{* * *}$ & $90.00 \pm 1.56^{* * *}$ \\
Group II: Diabetic control & $209.70 \pm 2.52$ & $256.14 \pm 1.86$ & $308.88 \pm 2.94$ & $261.72 \pm 1.92$ & $322.74 \pm 3.06$ \\
Group III: MET $50 \mathrm{mg} / \mathrm{kg}$ & $224.28 \pm 4.02$ & $157.50 \pm 1.86^{* * *}$ & $99.54 \pm 1.62^{* * *}$ & $80.28 \pm 0.84^{* * *}$ & $76.68 \pm 1.92^{* * *}$ \\
Group IV: DPLME $400 \mathrm{mg} / \mathrm{kg}$ & $125.28 \pm 3.24^{* * *}$ & $112.68 \pm 2.28^{* * *}$ & $104.40 \pm 1.68^{* * *}$ & $95.04 \pm 1.14^{* * *}$ & $77.40 \pm 1.62^{* * *}$
\end{tabular}

Data are expressed as mean \pm SEM values $(n=6){ }^{* * *} p<0.001$ denotes statistically very significant result for a group when it was compared with the control group (Group II)

anti-hyperglycemic activity and it has been suggested that the presence of phytochemicals such as flavonoids, alkaloids and other phenolics may contribute to the activity [34]. Indeed, the role of flavonoids has already been reported in the stimulation of peripheral glucose uptake, enhancement of lipogenesis and facilitation of insulin release and conversion from pro-insulin to insulin [35]. Considering all these studies, it can be concluded that the antidiabetic and antihyperglycemic activities of the methanolic leaf extract of $D$. pentandra is mostly associated with its flavonoids content. These studies also suggest that $D$. pentandra methanolic leaf extracts could either stimulate the pancreatic insulin secreting cells or improve the receptor responsiveness of tissues to insulin for an increased glucose uptake. Alloxan is a chemical that confers its toxicological effects by the selective necrosis of pancreatic islet cells, leading to a 3 to 4 times increase in blood glucose levels compared to the untreated animals [36, 37]. It is possible that the administration of $D$. pentandra methanolic leaf extracts to alloxan-induced diabetic animals leads to elevated

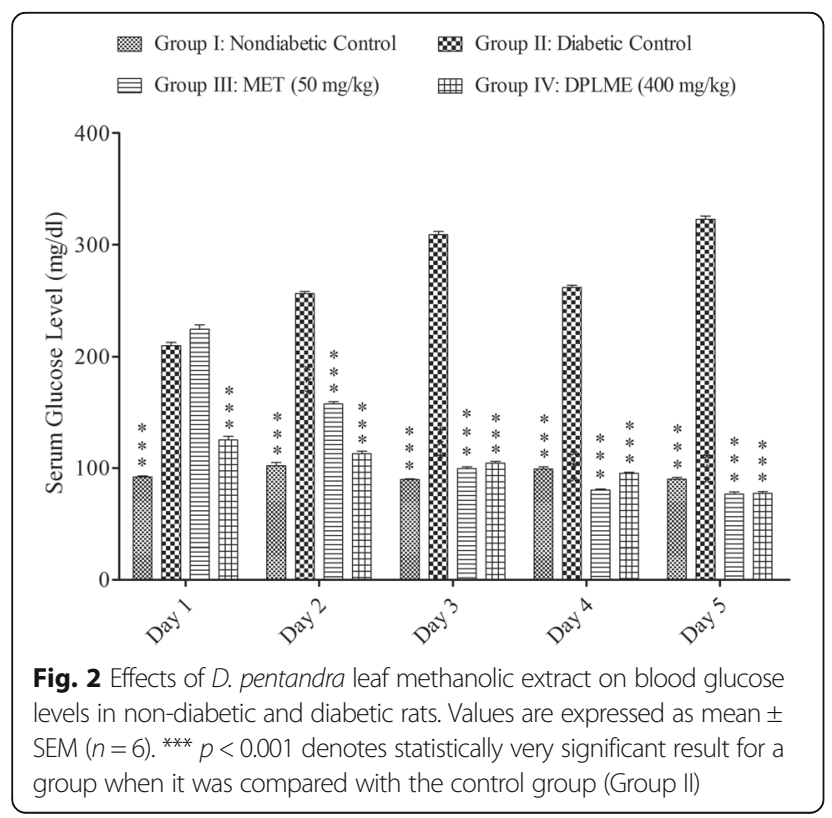

insulin secretion from regenerated or remnant beta cells or augmented stimulation of glucose uptake by peripheral tissues [38, 39].

The liver plays a vital role in the detoxification of a wide range of xenobotics [40]. Liver damage mediated by the excessive exposure to drugs (e.g. high doses of paracetamol) and environmental pollutants leads to cellular necrosis, plasma membrane damage, depletion in glutathione (GSH) levels accompanied with elevated levels of serum markers of liver damage such as ALT, AST and alkaline phosphatase (ALP) [41]. The rise in total cholesterol, total bilirubin and hypoproteinemia are also key features of liver damage in PCM-intoxicated rats $[42,43]$. Several indigenous medicinal plants from the Indian sub-continent including, Bixa orellana, Cajanus cajan, Glycosmis pentaphylla and Casuarina equisetifolia are known to possess some hepatoprotective activity [44]. In our study, PCM-treated rats showed a significant rise in the levels of their liver function parameters (AST, ALT, total cholesterol, and total protein) while the levels were significantly lowered following administration of $D$. pentandra methanolic leaf extracts.

Table 3 Effect of methanolic leaf extract of D. pentandra on key liver function parameters of Rats having PCM induced hepatotoxicity

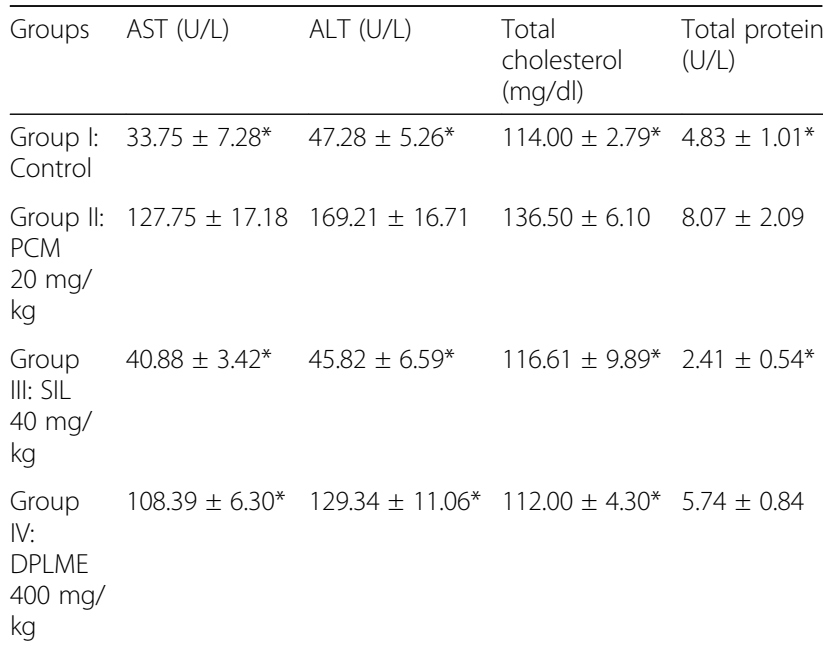

Data are expressed as mean \pm SEM $(n=4) .{ }^{*} p<0.05$ denotes statistically significant results for a group when it was compared with the PCM group (Group II) 


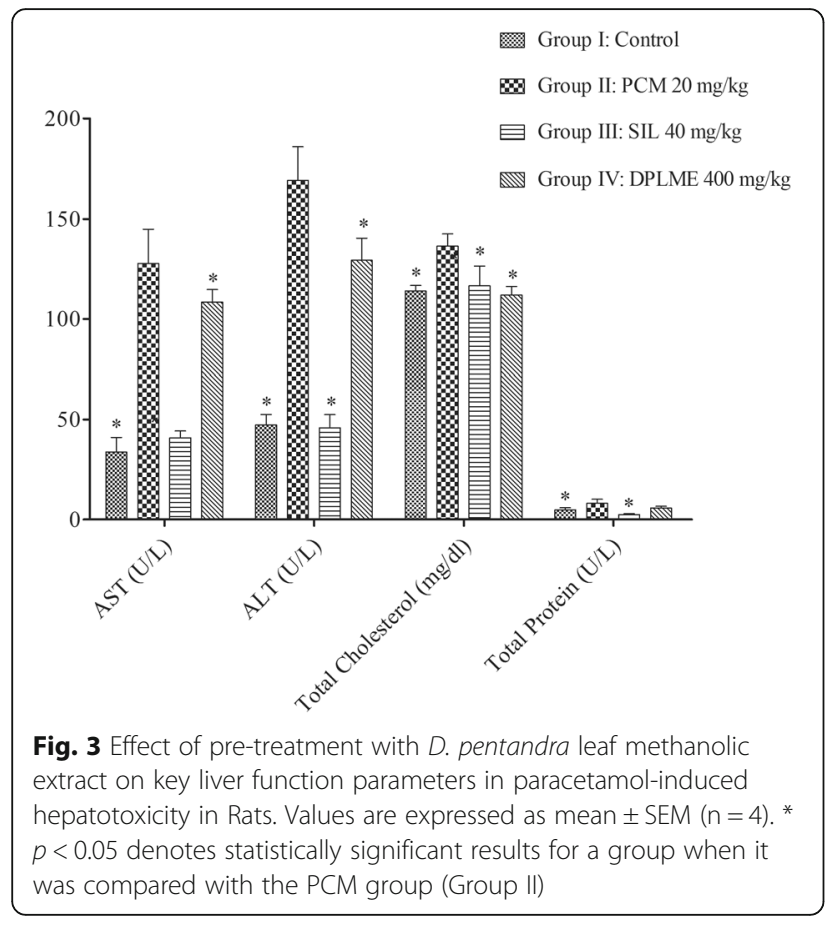

This hepatoprotective effect was comparable to the one observed for rats treated with silymarin, a popular hepatoprotective herbal remedy prepared from Silybum marianum (milk thistle) $[45,46]$. Various secondary metabolites have been identified in the leaf extract of $D$. pentandra including flavonoids, alkaloids, saponins and tannins. Flavonol glycosides i.e., quercetin-3-O-rhamnoside was also isolated from this plant extract $[2,32,33]$. These secondary metabolites have been reported to be associated with the hepatoprotective effects of different medicinal plants $[47,48]$. The observed hepatoprotective effect of D. pentandra extract might be associated with the presence of these flavonol as well as other secondary metabolites. It is possible that $D$. pentandra extracts help improve the functions of hepatocytes by stabilising cell membranes and/or enhancing the regeneration of parenchymal cells [11]. Overall, this suggests that $D$. pentandra methanolic leaf extracts can effectively control liver damage and restore liver functions.

\section{Conclusions}

Our results have highlighted, for the first time, the antihyperglycemic, antidiabetic and hepatoprotective activity of the methanolic extract of $D$. pentandra leaves in vivo. Further research aimed at the elucidation of key phytochemicals responsible for the observed effects is necessary to consolidate the use of this medicinal plant as a therapeutic option for the treatment of hepatic injuries and diabetes.

\section{Abbreviations}

ALT: Alanine aminotransferase; AST: Aspartate aminotransferase; DPLME: D. pentandra leaf methanolic extract; MET: Metformin; OGTT: Oral glucose tolerance test; PCM: Paracetamol; SEM: Standard error of the mean; SIL: Silymarin

\section{Acknowledgements}

The authors acknowledge the Department of Pharmacy, School of Science and Engineering, Southeast University, Dhaka, Bangladesh for providing support and necessary research facilities to conduct this study.

\section{Funding}

This research work did not receive any specific funding.

\section{Authors' contributions}

$\mathrm{MH}$ and $\mathrm{LN}$ conceived and designed the experiments; $\mathrm{MH}$ and RA performed the experiments; MH and MTA analysed the data; MTA, RK, PP, Al, and VS wrote the paper. All authors read and approved the manuscript.

\section{Ethics approval}

All the experimental rats were treated following the Ethical Principles and Guidelines for Scientific Experiments on Animals (1995) formulated by The Swiss Academy of Medical Sciences and the Swiss Academy of Sciences. The Institutional Animal Ethical Committee of Southeast University, Bangladesh approved all experimental rules.

\section{Competing interests}

The authors declare that they have no competing interests.

\section{Author details}

${ }^{1}$ Department of Pharmacy, School of Science and Engineering, Southeast University, Banani, Dhaka 1213, Bangladesh. ${ }^{2}$ Department of Biochemistry and Molecular Biology, Faculty of Biological Sciences, University of Dhaka, Dhaka 1000, Bangladesh. ${ }^{3}$ Department of Pharmacy, Faculty of Sciences and Engineering, East West University, Dhaka 1212, Bangladesh. ${ }^{4}$ Natural Products Drug Discovery Research Group, Strathclyde Institute of Pharmacy and Biomedical Sciences, University of Strathclyde, Glasgow, UK.

Received: 23 January 2018 Accepted: 27 May 2018

Published online: 26 June 2018

\section{References}

1. Endharti AT, Permana S. Extract from mango mistletoes Dendrophthoe pentandra ameliorates TNBS-induced colitis by regulating CD4+ T cells in mesenteric lymph nodes. BMC Complement Altern Med. 2017;17(1):468.

2. Syazana NA, Zainuddin NASN, Sul'ain MD. Phytochemical analysis, toxicity and cytotoxicity evaluation of Dendropthoe pentandra leaves extracts. Int J Appl Biol Pharm. 2015;6:109-16.

3. Artanti N, Ma'arifa $Y$, Hanafi M. Isolation and identification of active antioxidant compound from star fruit (Averrhoa carambola) mistletoe (Dendrophthoe pentandra L.) Miq. Ethanol extract. J Appl Sci. 2006;6:1659-63.

4. Ang HY, Subramani T, Yeap SK, Omar AR, Ho WY, Abdullah MP, et al. Immunomodulatory effects of Potentilla indica and Dendrophthoe pentandra on mice splenocytes and thymocytes. Exp Ther Med. 2014;7(6):1733-7.

5. Wild SH, Roglic G, Green A, Sicree R, King H. Global prevalence of diabetes: estimates for the year 2000 and projections for 2030: response to Rathman and Giani. Diabetes Care. 2004;27(10):2569.

6. David EJ, Ohio James MF. Evaluation and prevention of diabetic neuropathy. Am Fam Physician. 2005;71(11):2123-8.

7. Kristova V, Liskova S, Sotnikova R, Vojtko R, Kurtanský A. Sulodexide improves endothelial dysfunction in streptozotocin-induced diabetes in rats. Physiol Res. 2008;57(3):491-4.

8. Chaudhury A, Duvoor C, Dendi VSR, Kraleti S, Chada A, Ravilla R, et al. Clinical review of antidiabetic drugs: implications for type 2 diabetes mellitus management. Front Endocrinol. 2017;8:6.

9. Muniyappa R, Lee S, Chen H, Quon MJ. Current approaches for assessing insulin sensitivity and resistance in vivo: advantages, limitations, and appropriate usage. Am J Physiol Endocrinol Metab. 2008;294(1):E15-26.

10. Byass $P$. The global burden of liver disease: a challenge for methods and for public health. BMC Med. 2014;12(1):159. 
11. Chattopadhyay RR. Possible mechanism of hepatoprotective activity of Azadirachta indica leaf extract: part II. J Ethnopharmacol. 2003;89(2):217-9.

12. Rajagopal K, Sasikala K. Antihyperglycaemic and antihyperlipidaemic effects of Nymphaea stellata in alloxan-induced diabetic rats. Singap Med J. 2008; 49(2):137-41.

13. Mukherjee PK, Sahoo AK, Narayanan N, Kumar NS, Ponnusankar S. Lead finding from medicinal plants with hepatoprotective potentials. Expert Opin Drug Discov. 2009;4(5):545-76.

14. Alberti KGMM, Zimmet PZ. Definition, diagnosis and classification of diabetes mellitus and its complications. Part 1: diagnosis and classification of diabetes mellitus. Provisional report of a WHO consultation. Diabet Med. 1998;15(7):539-53.

15. Newman DJ, Cragg GM. Natural products as sources of new drugs over the last 25 years $\perp$. J Nat Prod. 2007;70(3):461-77.

16. Mathew S, Abraham TE. In vitro antioxidant activity and scavenging effects of Cinnamomum verum leaf extract assayed by different methodologies. Food Chem Toxicol. 2006;44(2):198-206.

17. Joy K, Kuttan R. Anti-diabetic activity of Picrorhiza kurroa extract. J Ethnopharmacol. 1999:67(2):143-8.

18. Hönes J, Müller $P$, Surridge $N$. The technology behind glucose meters: test strips. Diabetes Technol Ther. 2008:10(Suppl 1):10-26.

19. Kumar D, Kumar S, Kohli S, Arya R, Gupta J. Antidiabetic activity of methanolic bark extract of Albizia odoratissima Benth. In alloxan induced diabetic albino mice. Asian Pac J Trop Med. 2011;4(11):900-3.

20. Barham D, Trinder P. An improved colour reagent for the determination of blood glucose by the oxidase system. Analyst. 1972;97(151):142-5.

21. Achliya GS, Wadodkar SG, Dorle AK. Evaluation of hepatoprotective effect of Amalkadi Ghrita against carbon tetrachloride-induced hepatic damage in rats. J Ethnopharmacol. 2004;90(2-3):229-32.

22. Gowda S, Desai PB, Hull W, Math AAK, Vernekar SN, Kulkarni SS. A review on laboratory liver function tests. Pan Afr Med J. 2009;3:17.

23. Petrovska BB. Historical review of medicinal plants' usage. Pharmacogn Rev. 2012;6(11):1-5

24. Balunas MJ, Kinghorn AD. Drug discovery from medicinal plants. Life Sci. 2005;78(5):431-41.

25. Eddouks $M$, Maghrani $M$, Lemhadri A, Ouahidi $M-L$, Jouad $H$. Ethnopharmacological survey of medicinal plants used for the treatment of diabetes mellitus, hypertension and cardiac diseases in the south-east region of Morocco (Tafilalet). J Ethnopharmacol. 2002;82(2):97-103.

26. Klein R. Hyperglycemia and microvascular and macrovascular disease in diabetes. Diabetes Care. 1995;18(2):258-68.

27. Bolen S, Feldman L, Vassy J, Wilson L, Yeh H-C, Marinopoulos S, et al. Systematic review: comparative effectiveness and safety of oral medications for type 2 diabetes mellitus. Ann Intern Med. 2007;147(6):386-99.

28. Endharti AT, Wulandari A, Listyana A, Norahmawati E, Permana S. Dendrophthoe pentandra (L.) Miq. Extract effectively inhibits inflammation, proliferation and induces p53 expression on colitis-associated colon cancer. BMC Complement Altern Med. 2016;16(1):374

29. Elsyana V, Bintang M, Priosoeryanto BP. Cytotoxicity and antiproliferative activity assay of clove mistletoe (Dendrophthoe pentandra (L.) Miq.) leaves extracts. Adv Pharmacol Sci. 2016:2016:3242698.

30. Zamani A, Jusoh SAM, Al-Jamal HAN. Sul'ain MD, Johan MF. Antiproliferative effects of Dendrophthoe pentandra methanol extract on BCR/ $\mathrm{ABL}$-positive and imatinib-resistant leukemia cell lines. Asian Pac J Cancer Prev. 2016;17(11):4857-61.

31. Foretz M, Guigas B, Bertrand L, Pollak M, Viollet B. Metformin: from mechanisms of action to therapies. Cell Metab. 2014;20(6):953-66.

32. Fitrilia $T$, Bintang $M$, Safithri $M$. Phytochemical screening and antioxidant activity of clove mistletoe leaf extract (Dendrophthoe pentandra (L.) Miq.). IOSR J Pharm. 2015;5(8):13-8.

33. Yee L, Fauzi N, Najihah N, Daud N, Sulain M. Study of Dendrophthoe pentandra ethyl acetate extract as potential anticancer candidate on safety and toxicity aspects. J anal. Pharm Res. 2017;6(1):00167.

34. Grover J, Yadav S, Vats V. Medicinal plants of India with anti-diabetic potential. J Ethnopharmacol. 2002;81(1):81-100.

35. Cordero-Herrera I, Martín MA, Bravo L, Goya L, Ramos S. Cocoa flavonoids improve insulin signalling and modulate glucose production via AKT and AMPK in HepG2 cells. Mol Nutr Food Res. 2013;57(6):974-85.

36. Szkudelski T. The mechanism of alloxan and streptozotocin action in B cells of the rat pancreas. Physiol Res. 2001;50(6):537-46.
37. Zhang $X$, Liang W, Mao Y, Li H, Yang Y, Tan H. Hepatic glucokinase activity is the primary defect in alloxan-induced diabetes of mice. Biomed Pharmacother. 2009;63(3):180-6.

38. Grover J, Vats V, Rathi S. Anti-hyperglycemic effect of Eugenia jambolana and Tinospora cordifolia in experimental diabetes and their effects on key metabolic enzymes involved in carbohydrate metabolism. J Ethnopharmacol. 2000;73(3):461-70.

39. Patel D, Prasad S, Kumar R, Hemalatha S. An overview on antidiabetic medicinal plants having insulin mimetic property. Asian Pac J Trop Biomed. 2012;2(4):320-30.

40. Ekins S, Wrighton SA. The role of CYP2B6 in human xenobiotic metabolism. Drug Metab Rev. 1999;31(3):719-54

41. Giannini EG, Testa R, Savarino V. Liver enzyme alteration: a guide for clinicians. Can Med Assoc J. 2005;172(3):367-79.

42. Wolf PL. Biochemical diagnosis of liver disease. Indian J Clin Biochem. 1999: 14(1):59-90

43. Kumar G, Banu GS, Pappa PV, Sundararajan M, Pandian MR. Hepatoprotective activity of Trianthema portulacastrum L. against paracetamol and thioacetamide intoxication in albino rats. J Ethnopharmacol. 2004;92(1):37-40.

44. Ahsan MR, Islam KM, Bulbul IJ, Musaddik MA, Haque E. Hepatoprotective activity of methanol extract of some medicinal plants against carbon tetrachloride-induced hepatotoxicity in rats. Eur J Sci Res. 2009;37(2):302-10.

45. Pradhan S, Girish C. Hepatoprotective herbal drug, silymarin from experimental pharmacology to clinical medicine. Indian J Med Res. 2006; 124(5):491-504.

46. Al-Sayed E, Martiskainen O, Seif el-Din SH, Sabra A-NA, Hammam OA, El-Lakkany NM, et al. Hepatoprotective and antioxidant effect of Bauhinia hookeri extract against carbon tetrachloride-induced hepatotoxicity in mice and characterization of its bioactive compounds by HPLC-PDA-ESI-MS/MS. Biomed Res Int. 2014:2014:245171.

47. Nithianantham K, Shyamala M, Chen Y, Latha LY, Jothy SL, Sasidharan S. Hepatoprotective potential of Clitoria ternatea leaf extract against paracetamol induced damage in mice. Molecules. 2011;16(12):10134-45.

48. Atta A, Elkoly T, Mouneir S, Kamel G, Alwabel N, Zaher S. Hepatoprotective effect of methanol extracts of Zingiber officinale and Cichorium intybus. Indian J Pharm Sci. 2010:72(5):564-70.

\section{Submit your manuscript to a SpringerOpen ${ }^{\circ}$ journal and benefit from:}

- Convenient online submission

- Rigorous peer review

- Open access: articles freely available online

- High visibility within the field

Retaining the copyright to your article

Submit your next manuscript at $>$ springeropen.com 